\title{
Patient Editorial Board for JNNP
}

\author{
Sara Riggare, Rick Thurbon, Sharon Roman, Tessa Richards, \\ Matthew C Kiernan
}

\section{JNNP strives to improve patient engagement in the studies that we publish}

At a recent BMJ Editor's retreat, as formal proceedings ended and the dinner began, a late arrival and the need to squeeze in one more seat at the table resulted in the new direction you see, with the launch of a Patient Editorial Board. Following wide ranging discussions about patient involvement across all aspects of clinical research, a commitment was made to address ways to improve patient engagement in the studies that we publish. Establishment of an Editorial Board comprised solely of patients to help guide the journal, is part of a growing trend for greater consumer involvement across all walks of life in an attempt to refine and drive more meaningful exchanges and outcomes. Of relevance to neurology practice, a number of patient support groups have reacted to a perceived lack of progress in relation to discovery of new treatments and investigation of rare neurological diseases. To date, rare diseases seem to have been left in the wake of the more prominent conditions. This has become increasingly apparent in the realm of neurodegenerative disease where patient groups have broadly questioned the direction of research. Specifically, questions have arisen about the suitability of clinical trial models particularly for conditions where there is significant heterogeneity, even if the diagnosis is the same. In contrast, specialties such as oncology are accelerating towards targeted and individualised precision approaches, while for neurodegenerative disease such approaches are languishing. Patients complain that their voices are disappearing into large multicentre trials, many of which still result in negative outcomes. Patients have argued that the clinical trial model, built around incremental refinements to treat large patient populations, seems poorly designed to tackle many of the diseases we encounter as neurologists. Separately, discussions are also beginning to focus on concepts around perception of clinical significance-what a scientific

Journal of Neurology, Neurosurgery and Psychiatry Editorial Office, BMJ Publishing Group, London, UK

Correspondence to Professor Matthew C Kiernan, Journal of Neurology, Neurosurgery and Psychiatry Editorial Office, BMJ Publishing Group, London, UK; jnnp@bmj.com manuscript suggests as statistically significant, individual patients may challenge as being of no use to them in day-to-day life.

Increasingly, patient support groups are encouraging clinicians to focus on the issues that confront them as patients, and further, to turn their attention to more ambitious projects, rather than incremental change. Criticism has been levelled that too much time is being spent on securing grant renewals and flawed metrics like impact factor and individual $\mathrm{H}$ index, rather than real impact. To guide this process in a more positive direction, there is a move towards involving patients throughout research projects in addition to the clinical trial design process, with ongoing communication and collaboration setting the benchmarks. In doing so, patients are advocating for scientists, medical publishers, charities and public funding institutions to join together to promote more meaningful dialogue and change.

In terms of practical everyday approaches, evidence is growing to support the role of multidisciplinary care for people with progressive neurological disease-to provide multidimensional assessment, symptom management and care-planning allowing patients to better live with disease. However, the joining-up of health and community service providers to meet patient needs and preferences is currently more ambition than reality. While disability insurance schemes are struggling with implementation globally, patient-reported outcomes have similarly struggled to be heard. As such, there remains a significant challenge of cohesion, with a need across patient organisations to develop cogent, coordinated policies that recognise the potential of duplication and inefficiencies between the competing priorities of drug discovery, clinical trials, service delivery and research funding. In addition, there are differing local and nationwide approaches to funding specialised clinical services, teaching hospitals and community care.

To improve these services, it is imperative that leading clinical and research groups link with patient-centred organisations, care providers and philanthropy to develop national and international consortia that will accumulate real-time, quality-controlled data to inform best practice service provision, research and enrolment in clinical trials. A further problem that has been identified over the course of wide-ranging research projects, remains that data collection systems have grown organically. As such, it is imperative that we work towards consolidation, making data collection more patient focussed while also providing better feedback to patients, carers and clinicians. The outcome of such an approach will be to provide relevant data across the spectrum of care, service provision and research informing more accurate policy development. Separately, it is critical for effective distribution of health dollars that policy development keeps pace with scientific discovery, technology given that ageing populations result in an escalating prevalence of progressive neurological disease.

Clearly, effective policy development will be needed to drive better care for people living with neurological disease, while also supporting their carers. However, the imperative for all stakeholders will remain to find a cure for each disease. Policy needs to balance these competing goals-delivering better care today, while researching better outcomes for tomorrow. In that realm, we need better ways to integrate our ever increasing pools of data. The allocation of funding (government, industry and philanthropy) towards these goals will be more transparent when informed by reliable data and evidence-based hypotheses. With good data and strong consumer input, the collective stakeholders in patient partnership models will be well positioned to develop a common agenda and equitable policy direction. The overarching aim of any partnership should be to empower patients and to maximise participationfrom data collection through to policy development and implementation, with translation into practice and thereby improved outcomes. ${ }^{12}$ Better access to reliable data to make better sense of living with disease, to underpin better care and the hope of effective research should become the gold standard. Accordingly, consumer participation is central to all of us. By launching this further initiative for JNNP, we hope to gather constructive and practical contributions, while also remembering that there can be no single approach to partnership. The patients now listed on the Editorial Board will consider best ways to grow this partnership, from editorial commentaries ${ }^{3}$ and ongoing selections of the monthly Patient Choice articles, ${ }^{4-6}$ that will be freely downloadable through 
the journal website (https://jnnp.bmj. com), through to podcasts and further unique patient-centric approaches.

Funding The authors have not declared a specific grant for this research from any funding agency in the public, commercial or not-for-profit sectors.

Competing interests None declared.

Patient consent for publication Not required.

Provenance and peer review Commissioned; internally peer reviewed.

(c) Author(s) (or their employer(s)) 2019. No commercial re-use. See rights and permissions. Published by BMJ.

A Check for updates
To cite Riggare S, Thurbon R, Roman S, et al. J Neurol Neurosurg Psychiatry 2019;90:369-370.

Received 22 January 2019

Accepted 22 January 2019

\section{Linked}

- http://dx.doi.org/10.1136/jnnp-2019-320455

J Neurol Neurosurg Psychiatry 2019;90:369-370. doi:10.1136/jnnp-2019-320453

\section{REFERENCES}

1 Wicks P, Richards T, Denegri S, et al. Patients' roles and rights in research. BMJ 2018;362.

2 Richards T, Schroter S, Price A, et al. Better together: patient partnership in medical journals. BMJ 2018;362.
3 Roman S. The real p(atient) value. J Neurol Neurosurg Psychiatry 2019;90:371.

4 Noble AJ, Reilly J, Temple J, et al. Cognitive-behavioural therapy does not meaningfully reduce depression in most people with epilepsy: a systematic review of clinically reliable improvement. J Neurol Neurosurg Psychiatry 2018;89:1129-37.

5 Saxena A, Jones L, Shankar R, et al. Sudden unexpected death in epilepsy in children: a focused review of incidence and risk factors. J Neurol Neurosurg Psychiatry 2018:89:1064-70.

6 Ziff OJ, Banerjee G, Ambler G, et al. Statins and the risk of intracerebral haemorrhage in patients with stroke: systematic review and meta-analysis. J Neurol Neurosurg Psychiatry 2019:90:75-83. 